\title{
URBANIZAÇÃO TURÍSTICA E PRODUÇÃO DO ESPAÇO NA CIDADE DE CABO FRIO - RJ: UM BALANÇO CRÍTICO (1997-2018)
}

Tourism urbanization and space production in the city of Cabo Frio - RJ: A critical balance (1997-2018)

Leandro Dias de Oliveira

Professor Associado - Departamento de Geografia Professor do Quadro Permanente do Programa de Pós-Graduação em Geografia da Universidade Federal Rural do Rio de Janeiro (UFRRJ) ldiasufrrj@gmail.com

Felipe de Souza Ramão Doutorando em Políticas Públicas e Formação Humana pela UERJ Professor da Rede Municipal de Ensino de Cabo Frio - RJ felipesouzaspa@gmail.com

Gilmar Mascarenhas Professor Titular - Instituto de Geografia Professor do Quadro Permanente do Programa de Pós-Graduação em Geografia Universidade do Estado do Rio de Janeiro (UERJ) gilmasc2001@yahoo.com.br

Este texto foi construído entre setembro de 2017 e abril de 2019, fruto da conjugação de esforços dos autores com o objetivo comum de pensar a cidade de Cabo Frio, as suas transformações econômico-espaciais e adoção do processo de urbanização turística. Ele nasceu de uma retomada de debates realizados na década anterior, que ainda não tinham recebido $o$ tratamento conceitual adequado $e$ prescindiam de um balanço crítico.

Encontrava-se, assim, em processo de revisão final para publicação quando, infortunadamente, Gilmar Mascarenhas teve sua vida interrompida de forma brusca, em junho de 2019, pela brutalidade da supremacia de carros e ônibus junto ao desrespeito ao ciclista urbano.

Reforçamos, acima de tudo, que Gilmar Mascarenhas deixou um grande legado: sua vasta obra é referência em diferentes estudos da geografia, do turismo e do lazer, e sua luta por uma cidade mais justa, democrática e humana permanece viva em nossas memórias.

Assim, dedicamos honradamente esse artigo à memória de nosso amigo Gilmar Mascarenhas, que consagrou sua carreira acadêmica à geografia, aos estudos urbanos e ao pensamento crítico.

Enviado em 03/10/2019 e aceito para publicação em 26/05/2020

DOI: $10.12957 /$ tamoios.2020.45750 


\title{
Resumo
}

Cabo Frio, cidade fluminense situada na Região das Baixadas Litorâneas, tem vivenciado desde a década de 40 do século passado um processo de urbanização turística. Todavia, é durante os vinte anos consecutivos de administração municipal de Alair Correa e Marcos da Rocha Mendes que a cidade investiu maciçamente nesta via de produção do espaço urbano. O objetivo deste artigo é realizar um balanço crítico deste período no que se refere ao modelo urbano adotado.

Palavras-chave - Urbanização turística; transformações urbanas; segregação espacial; Cabo Frio; Região dos Lagos.

\begin{abstract}
The city of Cabo Frio, located in the Região das Baixadas Litorâneas - Rio de Janeiro, has lived since the 40's of last century a process of tourist urbanization. However, in the twenty years of local management of Alair Correa and Marcos da Rocha Mendes the city invests massively in this way of production of urban space. This article aims to evaluate this urban model adopted.
\end{abstract}

Keywords - Tourism urbanization; urban transformations; spatial segregation; Cabo Frio; Região dos Lagos.

\section{Introdução}

A cidade de Cabo Frio, situada na Região das Baixadas Litorâneas, apresenta importância estratégica para o turismo fluminense. Se historicamente a cidade apresentou economia baseada na atividade pesqueira e na extração do sal, atualmente sobrevive por meio de uma produção limitada e direcionada para mercados específicos. Cabo Frio se consolidou como uma cidade média dinâmica com grande expansão imobiliária recente.

Inspirados nos esforços Andrade e Serra (2001) e Maria Encarnação Beltrão Sposito (1999 e [et.al.] 2006), indicamos que Cabo Frio é uma cidade média por representar uma centralidade econômica em relações às cidades contíguas, oferecendo uma série de serviços - comerciais, instrucionais, informacionais, médico-hospitalares, culturais - que não existem nas cidades pequenas. Araruama, São Pedro da Aldeia, Saquarema, Iguaba Grande, Arraial do Cabo, Armação dos Búzios são destacadamente cidades que se articulam sob influência cabofriense ${ }^{1}$. A centralidade de Cabo Frio se manifestava com pujança desde o século XIX e até a primeira metade do século XX enquanto a atividade salineira era a principal fonte econômica regional, contando ainda com as cidades que eram distritos cabo-frienses - São Pedro da Aldeia, Arraial do Cabo e Armação dos Búzios, emancipadas respectivamente em 1892, 1985 e 1995. Tal polarização permaneceu com o advento, crescimento e consolidação do turismo como atividade econômica regional central.

Cidades médias são, nesta leitura, "espaços luminosos" emergentes de desenvolvimento. Apesar disso, Cabo Frio - e também as outras cidades médias da região - não romperam com certas características do espaço rural e, portanto, admitem na contemporaneidade a existência de um continuum rural-urbano ou de uma urbanização incompleta, ao contrário dos grandes centros que já conheceram um profundo e abrangente processo de urbanização. Cabo Frio não é somente seu centro 
turístico-econômico, mas compreende ainda grandes áreas com características protourbanas, em particular em seu segundo distrito, Tamoios.

Logo, a migração de empresas, população e recursos em direção às cidades médias brasileiras nas últimas décadas revelam o próprio espraiamento da vida metropolitana para além de sua região delimitada oficialmente. Sandra Lencioni (2015) apresentou a expressão "nebulosa urbana" como interpretação do fenômeno, numa conformação de uma megarregião fruto da urbanização dispersa que envolve a implosão e explosão da cidade (LEFEBVRE, 1999 [1970]) e a própria dinâmica de concentraçãodispersão das atividades econômicas, de pessoas e riquezas no atual processo de megapolização Rio de Janeiro-São Paulo. Permite-se assim ir além da rigidez classificatória da megalópole como uma mancha urbana cartográfica homogênea e superpovoada.

A parte fluminense desta megarregião é composta inicialmente por cinquenta municípios - extrapolando, portanto, as cidades que compõem a Região Metropolitana do Rio de Janeiro - e seu limite seria num primeiro momento justamente a cidade de Cabo Frio, revelando a sua importância "metropolitana". Esta expansão "megalopolitana" baliza o movimento global de mudanças na produção e gestão das cidades, estimulando interpretações e ações que envolvam o léxico empresarial da questão urbana contemporânea, como governança, produtividade e competitividade.

Nesta atmosfera de competitividade espacial, o investimento público em turismo recebe crescente atenção, especialmente nas cidades médias. Tal iniciativa do poder local busca atrelar à imagem da cidade aspectos valorizados no mercado dos lugares, tais como "dinamismo", "juventude”, "organização", "alegria”, "qualidade de vida", "sustentabilidade", que se tornam vulgarizados e esvaziados para além dos dogmas empresariais. Em concomitância a isto, o investimento público não se revela propriamente uma política de incremento do lazer da população, mas se materializa em projetos de instalações monumentais, de grande visibilidade e centralidade na paisagem urbana. O lazer, afinal, se consolida como um atrativo voltado para o mercado com capitalização do tempo livre dos visitantes, mas também como uma importante estratégia de atração imobiliária para aqueles que desejam fugir dos grandes problemas dos núcleos metropolitanos e das demais grandes cidades, tornando-se um álibi para as intervenções de promotores imobiliários e do poder público (DANTAS, FERREIRA, CLEMENTINO, 2010).

Se a implementação do turismo como atividade econômica central na cidade de Cabo Frio remete à segunda metade do século XX, neste artigo o objetivo é analisar a reestruturação urbana da cidade a partir da década de 1990, pela perspectiva conceitual desenvolvida por Patrick Mullins (1991), no que este autor australiano denominou de urbanização turística, temática também explorada, por exemplo, por Edmilson Lopes Jr. (2000) e Maria Tereza Luchiari (1998). A urbanização turística de Cabo Frio esteve peremptoriamente baseada numa conjuntura de crescimento de verbas procedentes da economia dos royalties para a cidade (PESSANHA, 2015) e de um projeto político que se consolidou nos últimos vinte anos (1997-2017).

Cabo Frio não é uma cidade produtora de petróleo, mas apenas petrorrentista, e assim os altos valores de royalties recebidos acabam sendo geralmente direcionados na sua reestruturação urbana, de acordo com as prioridades da Administração Municipal (OLIVEIRA, RIBEIRO, 2009). Praticamente toda a região Norte Fluminense e grande parte da Região das Baixadas Litorâneas têm nos valores dos royalties recebidos parte significativa de sua arrecadação (MENEZES, 2008). Assim, o que este artigo propõe é investigar algumas das transformações recentes ocorridas em Cabo Frio, decorrentes do processo que pode ser sinteticamente intitulado de turistificação. Concentraremos nosso 
foco na produção da paisagem associada ao discurso de lazer, identificando monumentos e projetos de urbanização que simbolizam tal proposta.

\section{Urbanização turística e produção do espaço urbano}

Entre as práticas espaciais mais evidentes e características dos tempos atuais desponta o turismo, que envolve cada vez mais sujeitos entrelaçados econômica, sociocultural e ambientalmente (FENNELL, 2002). A matéria-prima desta atividade econômica é o próprio espaço geográfico, transformado em mercadoria enquanto lugar turístico. Como nova modalidade de consumo, o turismo gera a reprodução e comércio do espaço (FRATUCCI, 2001), promovendo um ordenamento territorial específico aliado à expansão da produção de bens e serviços. A paisagem, tornada vitrine e fluidificada para o consumo de massa e ideologicamente estilizada para a atração dos turistas, é atrelada à necessidade do lazer e do descanso e diretamente relacionada aos elementos da natureza.

$\mathrm{Na}$ geografia econômica do turismo cola-se uma etiqueta de preço em cada beleza natural. Henri Lefebvre (2006 [1968]) descreve a mudança entre a cidade da Idade Média, ornamentada para o morador, para a cidade turística, que carrega a característica de ser consumida pelos turistas. Nesta paisagem fetichizada, a sua apreensão extrapola o visível, pois as sensações e o ambiente da cidade turística são também vendidas e consumidas, transformando o tempo livre do trabalhador em mercadoria (PORTO-GONÇALVES, 2002).

A produção e gestão do urbano se voltam para a espetacularização e maior projeção global, se revestindo de valores e estratégias neoliberais, naquilo que David Harvey (2005) identificou como empresariamento (ou empreendorismo) urbano. O autor aponta a década de 1970 como ponto de inflexão da reestruturação da economia mundial, com a transição progressiva e incompleta de um regime fordista-keynesiano para um regime flexível de produção, que reverbera, no plano da gestão urbana, na mudança do paradigma do administrativismo para o empreendedorismo urbano. As construções de complexos turísticos e de lazer, centros de exposição, museus, shopping centers, revitalização de centros históricos, além da realização de grandes eventos com seus ícones arquitetônicos e seus recintos de consumo exclusivo e hedonista, são intervenções que compõem o repertório de ações do modelo empreendedorista, acentuando a competição entre cidades no cenário global (COMPANS, 2004). Surgem, assim, projetos fabulosos que incidem sobre os espaços das cidades, alterando-os de forma cada vez mais incisiva e que resultam em maior visibilidade e atratividade turística (MASSEY, 2007; WEED, 2008; KNAFOU, 2008; OLIVEIRA, 2014).

Otília Arantes (2000) já havia chamado a atenção para este processo de reformulação do planejamento urbano: o negócio das imagens como nova fronteira de acumulação e dinheiro, num verdadeiro culturalismo de mercado. Nesse sentido é necessário entender não apenas como os lugares adquirem qualidades materiais, mas também como eles adquirem valor simbólico mediante atividades de representação (LEFEBVRE, 1998). Por sua vez, Frederic Jameson (2000) salienta a integração crescente entre a estética e a produção de mercadorias, dentre estas, a própria cidade, e certamente o turismo tem se utilizado amplamente deste recurso. A gestão urbana empreendedorista pressupõe não apenas a presença de um governo local, mas uma coalizão de forças denominada de governança urbana, que tem como premissa a atuação conjunta do governo local, da iniciativa privada e da sociedade civil.

No bojo desta perspectiva empreendedorista de gestão urbana, podemos afirmar que uma cidade voltada para o turismo e veraneio tende a investir na construção de uma 
imagem que valorize suas belezas naturais, as amenidades ambientais e toda uma atmosfera lúdica, de modo a atrair novos moradores - efetivos ou sazonais - dispostos a pagar efetivamente pela "qualidade de vida" oferecida. Afinal, paraísos do capital imobiliário, este modelo de cidade evoca um estilo de vida saudável, alegre e relaxado (MASCARENHAS, 2004). Destarte, há uma verdadeira invenção da cidade turística, com a escolha premeditada de pontos históricos, culturais e ambientais que serão valorizados e vendidos como se representassem a totalidade do espaço da cidade, engendrado por um processo particular de produção do espaço a partir do modelo de urbanização turística.

A urbanização turística corresponde basicamente à constatação da existência de formas específicas de produção do espaço urbano constituídas a partir da atividade turística, sobretudo quando esta se impõe como dominante na economia local, em uma modalidade peculiar de produzir e estruturar o espaço. As cidades turísticas dedicam-se quase exclusivamente ao consumo, especialmente de artigos e serviços de diversão, prazer, relaxamento e recreação, e não aquele vinculado às necessidades básicas como moradia, serviços de saúde, abastecimento alimentar e educação (MASCARENHAS, 2004). Embora muitas destas cidades apresentem maior dinamismo econômico que a média ou ainda exerçam atração de fluxos migratórios em busca de oportunidades de renda e trabalho, o subemprego, a precarização dos contratos, o baixo índice de sindicalização e a baixa remuneração consistem na tônica dominante das cidades turísticas. No Brasil, malgrado a ausência de estudos sistemáticos a respeito, as evidências parecem confirmar este quadro social preocupante.

Para além das observações empíricas de Mullins, podemos sugerir um novo elemento como constituinte desta nova forma de organização do espaço urbano: a redefinição da noção de "usos sujos". O processo de modernização das cidades no mundo ocidental, que tem na reforma parisiense de Haussmann um dos paradigmas fundamentais, consistiu na aplicação de um urbanismo progressista, adequado ao advento da sociedade industrial (CHOAY, 1992). Neste se fez presente o higienismo, movimento de amplo espectro que preconizava no século XIX, com base nas descobertas epidemiológicas de vetores de doenças oriundos da microbiologia, uma profunda reestruturação do espaço urbano, circunscrevendo e eliminando usos e práticas consideradas nocivas à saúde pública. Em contextos específicos, tal discurso se adequou plenamente aos interesses do capital imobiliário e, de um modo geral, ao projeto elitista de gestão do espaço urbano, expulsando quiosques, cortiços e ambulantes das áreas nobres e centrais, em nome da higiene, da ordem e do embelezamento da cidade que se deseja moderna e cosmopolita, o que impõe uma reflexão sobre o direito à cidade, conforme ensinado por Henri Lefebvre (2011 [1968]).

No Brasil, este processo alterou profundamente a estrutura de nossas cidades, conduzindo à formação das favelas e expansão de uma periferia empobrecida. No caso da urbanização turística, percebemos que a gestão do espaço amplia o rol dos usos considerados "sujos", isto é, inconvenientes em determinadas áreas privilegiadas para reprodução do capital. Se no período da Belle Époque se definiu como importante a construção de uma imagem de cidade ordeira, higiênica e progressista, na atualidade a atividade turística retoma como de suma importância a produção da imagem, por força da natureza intrínseca do produto que se vende. Mullins (1991) já chamava a atenção para a formação de enclaves como redutos espaciais de consumo hedonista - algo próximo ao que Henri Lefebvre (2006 [1968]) trata como guetos de lazer - fazendo com que os espaços de turismo na atualidade sejam voltados para o consumo de classes mais abastadas. Nestes espaços de realização dos "desejos", o bem-estar do turista não pode ser "ameaçado" pela presença de personagens e usos alheios à fantasia do consumo, 
fazendo com que a segurança também se torne um produto importante a ser vendido e garantido.

Por estes motivos, o crescimento demográfico numa cidade que privilegia as práticas turísticas e desenvolve uma espécie de ideologia do lazer presente no city marketing tende a ultrapassar as taxas médias regionais e mesmo a nacional, tanto em suas áreas centrais como em sua periferia, onde ficam relegadas as classes menos favorecidas e excluídas do modelo implantado nos espaços turistificados. Afinal, este modelo de urbanização pressupõe a construção de dimensões simbólicas e concretas de algumas cidades, acentuando a segregação urbana e excluindo grande parte de sua população do consumo de seus atrativos.

\section{As transformações urbanas da cidade de Cabo Frio}

A pesca foi a primeira atividade econômica de relevância na cidade de Cabo Frio, e, após o fim do "estanque do sal" (1801) - proibição de produção de sal pela Coroa Portuguesa -, a atividade salineira ganha projeção e passa a ser referência na cidade e em toda a região. A produção de sal no fim do século XIX e nas primeiras décadas do século XX apresentou tanto momentos de crise quanto de crescimento, o que se refletiu diretamente na variação da população urbana da região (CHRISTÓVÃO, 2011; MARAFON, 2005). Contudo, é somente com o turismo que a urbanização de Cabo Frio irá se consolidar.

O primeiro grande impulso do processo de urbanização turística reúne principalmente ações do poder público em diferentes esferas e do mercado imobiliário. Assim, entre as décadas de 1940 e 1960, tem-se: o plano Amaral Peixoto, do governo do estado do Rio de Janeiro, que projeta toda a Região dos Lagos enquanto turística; a criação de órgãos municipais para o planejamento do turismo na cidade de Cabo Frio; a criação do bairro Ogiva, por um grupo imobiliário do Rio de Janeiro, a construção de clubes de lazer e esporte, com forte vínculo também no Rio de Janeiro; uma expansão do processo de urbanização da lagoa para a praia do Forte (CHRISTÓVÃO, 2011; ALVES, 2011)

Na década de 1970, Cabo Frio já é um destino reconhecido e apreciado para parte da população da região metropolitana do Rio de Janeiro, com pessoas de classe mais abastada, personalidades artísticas e nomes de expressão política em residências secundárias, especialmente nos pontos próximos da Praia do Forte, nas margens da lagoa e no bairro Ogiva. Além destes, alguns outros poucos bairros recebiam esse morador temporário, bem como se preenchia a ainda incipiente rede hoteleira da cidade. A praia já se consolidava como o atrativo fundamental da cidade, a principal atividade de lazer e também o mais importante vetor de expansão urbana.

Um marco referencial no processo de urbanização turística da cidade de Cabo Frio e da relação com a cidade do Rio de Janeiro é a construção da Ponte Costa e Silva (Rio-Niterói), concluída em 1974. O encurtamento da distância entre a capital do estado do Rio de Janeiro e toda a Região dos Lagos impactou diretamente na cidade de Cabo Frio, que já exercia uma centralidade regional a partir do domínio econômico da indústria salineira, mas somente se firmou como referência a partir da incorporação e consolidação da atividade do turismo, com, por exemplo, a busca por serviços públicos e privados de pessoas de outros municípios na cidade.

A consolidação da cidade turística de Cabo Frio, algo que pode ser estendido para outras cidades turísticas, aconteceu fundamentalmente: [i] por um contexto econômico favorável ao surgimento e expansão dessa atividade, o que envolveu a busca por novas atividades, espaços e necessidades, num processo de acumulação do capital 
(HARVEY, 2005); [ii] pela combinação de dois fatores centrais, meio ambiente e infraestrutura, pela busca do "verde" e de regiões de praias fora dos grandes centros urbanos atrelada a uma tríade da infraestrutura - o acesso até a cidade, as condições e a qualidade da permanência do turista no local (GEORGE, 1973); por fim, [iii] pela necessidade de expansão da metrópole do Rio de Janeiro, a partir de ações e articulações que envolvem o poder público junto a expansão do mercado imobiliário e de serviços já consolidados ou em situação de saturação e espraiamento da Região Metropolitana.

Neste momento embrionário do turismo como atividade principal de Cabo Frio, havia graves problemas de infraestrutura local e de ligação com a região metropolitana do Rio de Janeiro, dificultando ampliação massiva do quantitativo de turistas e implicando em fatores limitantes para a expansão da própria atividade na cidade. Dessa forma, a combinação de investimento em infraestrutura básica com a melhoria na ligação entre a Região dos Lagos e a região metropolitana foram pontos cruciais para a consolidação do turismo enquanto atividade central da cidade, pois permitiram a aceleração do processo de urbanização turística, agregaram novos serviços complementares, estimularam a indústria da construção e a constituição de vários empreendimentos de diferentes origens.

Outro fator decisivo foi o enfraquecimento econômico da indústria salineira, que perdeu poder político na cidade de Cabo Frio, com a sucessão de períodos com prefeitos sem aliança com o setor e posteriormente com um grupo político voltado para o turismo (BAPTISTA, 2007). A indústria salineira perdeu territórios para o mercado imobiliário e assistiu à transformação das salinas desativadas em loteamentos, revelando que a cidade havia se tornado um grande campo de disputas entre diferentes frações do capital. Além disso, a fuga da violência urbana carioca, a implementação de novas estradas que ligam a Região das Baixadas Litorâneas à capital fluminense e a migração de trabalhadores desempregados foram também motivos para que a cidade de Cabo Frio apresentasse os maiores índices de crescimento populacional do estado (OLIVEIRA, 2003) na década de 1990. Os royalties da exploração de petróleo, a partir de 1997, considerando períodos de ascensão e crise econômica, e o fortalecimento do turismo nas últimas quatro décadas implicaram num ritmo de crescimento bem acima da média estadual e mesmo nacional.

Segundo Oliveira e Ribeiro (2009), para estimular o turismo, o poder público realizou nas últimas administrações obras de revitalização da cidade, como o calçamento e sinalização de ruas, obras de saneamento e escoamento de águas e recriações paisagísticas e estruturais. Entre 1997 e 2018, a administração municipal permaneceu com o mesmo grupo político, e sob os auspícios de Alair Correa (19972004; 2013-2016) e de Marcos da Rocha Mendes (2005 - 2012; 2017-2018) novas paisagens simbólicas foram criadas, com inspiração náutico-marinha e com destaque para a transformação estética do antigo "Canal do Itajuru" (renomeado para Boulevard Canal) e a remodelação da Praia do Forte, que recebeu um calçadão colorido complementado por um deck, bancos e luminárias, acrescidos da edificação das praças das Águas (Imagem 1) e da Cidadania (OLIVEIRA e RIBEIRO, 2009).

Mesmo sob o mesmo espectro político e ações governamentais semelhantes, as relações entre Marcos da Rocha Mendes e Alair Correa são complexas. Inicialmente, Marcos da Rocha Mendes rompeu com o antigo partido para se aliar a Alair Correa na eleição de 1996, tornando-se vice-prefeito nos dois mandatos (1997-2004). Posteriormente, foi eleito prefeito de Cabo Frio com o apoio de Alair Correa, mas durante seu primeiro mandato rompeu com o antigo parceiro político. A ruptura política fortaleceu a bipolaridade entre os dois líderes locais, bem como consolidou as 
tradicionais práticas de apadrinhamento e clientelismo entre seus grupos. As nuanças entre os dois prefeitos que dominam a política local nas últimas duas décadas, Alair Correa e Marcos da Rocha Mendes, são tênues, de maneira que formam um modelo único de fazer política que se consolidou no poder. Neste cenário de disputas políticas mas um só modelo de administração, houve constantemente a atualização da imagem da cidade, com a Prefeitura Municipal investindo, em diferentes momentos, na criação de slogans como "Cabo Frio: A cidade mais limpa do Brasil", "Cabo Frio: Cidade abençoada por Deus" e "Cabo Frio: A cidade para o cidadão”. Somente em 2018, com a cassação de Marcos da Rocha Mendes e novas eleições - nas quais ele foi, incrivelmente, candidato! -, foi eleito prefeito Adriano Guilherme de Teves Moreno, que rompeu os vinte anos de alternância entre apenas duas figuras políticas.

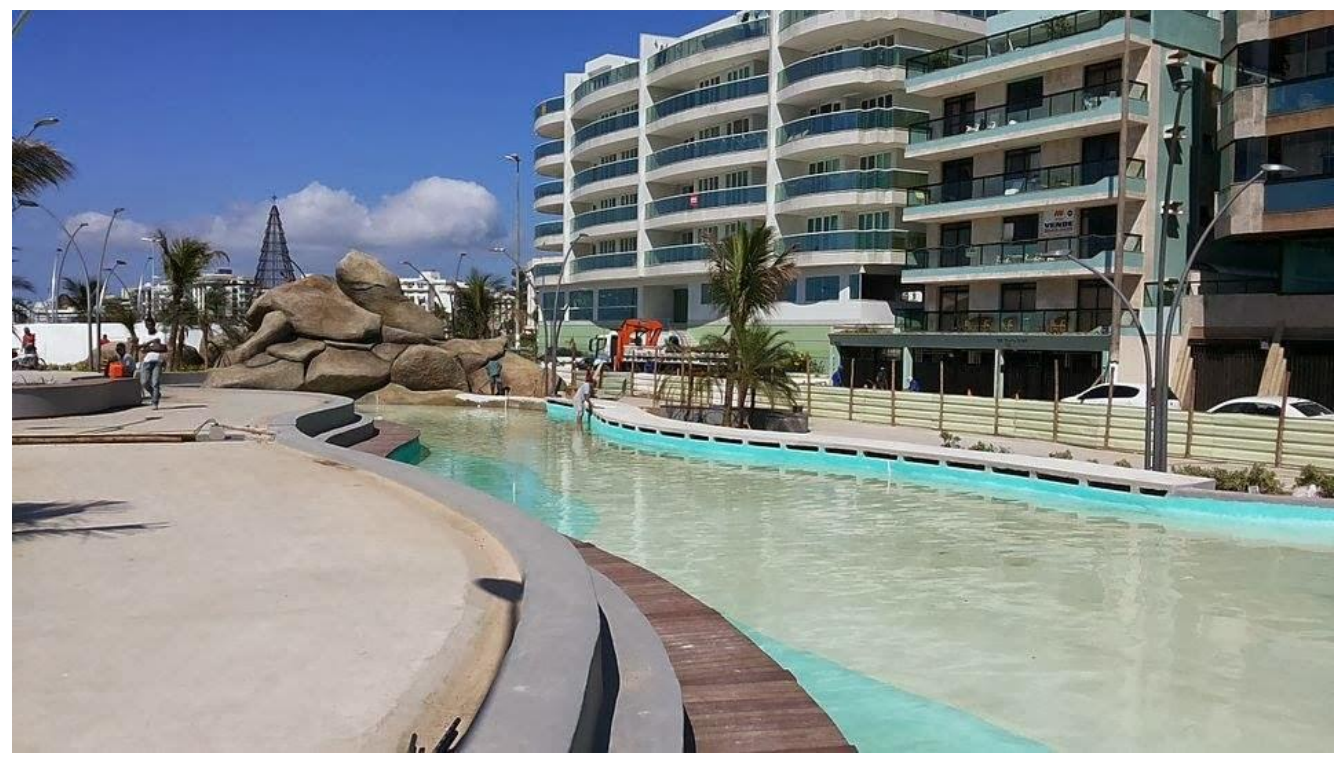

Imagem 1: Praça das Águas, na Praia do Forte: investimento no embelezamento urbano das áreas mais privilegiadas da cidade.

Fonte: http://cabofrioeshow.blogspot.com.br/2013/12/fonte-blog-reporter-renata-cristiane_26.Acesso em: 26 de fevereiro de 2018.

Assim, a construção de um suposto modelo ideal de qualidade de vida se consolidou como uma característica comum das cidades turísticas por todo o mundo. A promoção dessa imagem, pelo poder público e pelo mercado imobiliário, é algo fundamental para a concretização deste tipo de atividade econômica e para a atração de grandes fluxos de consumidores destes espaços. O interesse da criação dessa imagem objetiva a comercialização do espaço, que exige uma imagem que nem sempre é fiel à sua realidade concreta.

Mascarenhas e Oliveira (2006) destacam a importância do esporte nesta reestruturação em curso. A construção do Ginásio Poliesportivo de Cabo Frio, que sediou eventos nacionais de vôlei e futebol de salão, é um importante exemplo: este moderno ginásio, com piso dotado de amortecimento e painéis digitais de última geração, foi erguido em frente à Favela do Itajuru, revelando as contradições deste modelo de desenvolvimento (CONCEIÇÃO, 2008). A construção do Museu do Surf e das estátuas do jogador de futebol Leandro e do surfista Vitor Ribas, ambos cabofrienses, também simbolizaram a produção do urbano sob a temática do esporte.

Por fim, o investimento em eventos na cidade acaba por ser a coroação deste processo de construção simbólica do lazer no city marketing. A cidade de Cabo Frio esboçou um vasto calendário de festas e atividades diversas, que incluía desde torneios 
de modalidades esportivas náuticas, desfiles de moda, festas de dança ou temáticas aos tradicionais shows musicais durante o Carnaval, Semana Santa e Reveillon. A propaganda efetiva das administrações municipais de Cabo Frio permitiu incluir a cidade como em roteiros cada vez mais comuuns para visitas de grandes transatlânticos, que passaram a fazer parte da paisagem durante a alta estação.

A construção do shopping e a emersão dos loteamentos de luxo como o Alphaville consolidaram o impacto da urbanização turística. A edificação do resort Club Med numa área de natureza bastante intocada no bairro Peró, a edificação de diversos empreendimentos turísticos luxuosos, como o Marinas do Canal de Cabo Frio, com shopping e garagem para barcos, e o Mega Resort do Peró, anunciado pelo grupo do empresário Ricardo Amaral, Construtora Agenco (o mesmo da Vila do Pan, no Rio de Janeiro) seriam claros desdobramentos do processo. A Estrada de Guriri, que liga Cabo Frio até Búzios, é o acesso para estes grandes empreendimentos imobiliários e já foi completamente pavimentada, recebendo iluminação e sinalização. Como eixo da urbanização turística no território cabo-friense, a Estrada do Guriri sofreu abrupta valorização dos terrenos e viu emergir rapidamente diversos condomínios de classes médias e altas.

Neste mesmo contexto, nas duas últimas décadas o crescimento da rede hoteleira e de condomínios verticais nas proximidades da Praia do Forte e da Lagoa de Araruama (no Canal do Itajuru), destinados majoritariamente para a segunda residência, se tornou constante. $\mathrm{O}$ crescimento atual é talvez mais estratégico no ponto de vista espacial, por conta do alto valor do preço do solo, numa área com $\mathrm{o}^{2}$ mais caro da cidade, e da restrição de espaços ainda livres para a construção.

É fundamental reforçar a presença e ação de alguns grupos de origens específicas que dominam a cidade com seus empreendimentos. Trata-se do caso de empresas oriundas do Rio de Janeiro, como o exemplo do grupo João Fortes, que tem parcerias importantes com a empresa Modular (Cabo Frio) em construções de extremo luxo na cidade, como o Beach Side Residences e o Ocean Garden. Da mesma maneira, empresas de cidades mineiras Juiz de Fora, Belo Horizonte e Ubá, com grande destaque ao grupo NP (Ubá), construíram mais de quinze prédios da rede Barramares em Cabo Frio; são prédios divididos em um grupo mais antigo e funcional, e, um segundo grupo de prédios com maior tamanho, luxo e atrelado às ideias de sustentabilidade, conforto e qualidade, com três unidades localizadas na orla da Praia do Forte (Barramares X, XII e XV) e outros prédios nas proximidades da praia. Por fim, também há a participação de grupos estrangeiros no espaço mais valorizado da cidade, com destaque para a presença do grupo Best Western - que tem sua origem nos Estados Unidos, com mais de 60 anos de história, estando em mais de 100 países do mundo - com o hotel Paradiso Del Sol, sob o comando da Best Western América do Sul, localizado nas proximidades da lagoa e da Praia do Forte.

Assim, três pontos são fundamentais na compreensão desse processo recente de urbanização turística na cidade de Cabo Frio: [i] a centralidade dos espaços próximos à praia e da lagoa, que mesmo com o preço do solo alto receberam nos últimos anos novos empreendimentos pela possibilidade de maior valorização e por ainda conjugar infraestrutura e elementos do meio ambiente; [ii] a busca por novos espaços de acumulação, o que significa que da mesma forma que a cidade de Cabo Frio foi um espaço de expansão da metrópole do Rio de Janeiro e de empreendimentos de diferentes origens, no próprio processo de urbanização turística da cidade da Região das Baixadas Litorâneas novas rotas e rumos são fundamentais para a expansão, afastando-se dos espaços mais saturados, por meio de novos espaços com presença de empreendimentos e infraestrutura urbana; [iii] o meio ambiente passou a ser tanto alvo quanto obstáculo, 
pois é conservado, adaptado e comercializado, em exemplos de grandes empreendimentos como o Shopping Park Lagos (Imagem 2), que ignora regulamentos ambientais e cria inúmeros impactos ${ }^{2}$; por fim, [iv] a busca por um turista e um morador temporário cada vez mais vinculado às classes mais abastadas e disposto a investir grandes aportes financeiros em beleza natural, infraestrutura, segurança e conforto. Definitivamente, os novos empreendimentos buscam novos consumidores do espaço.

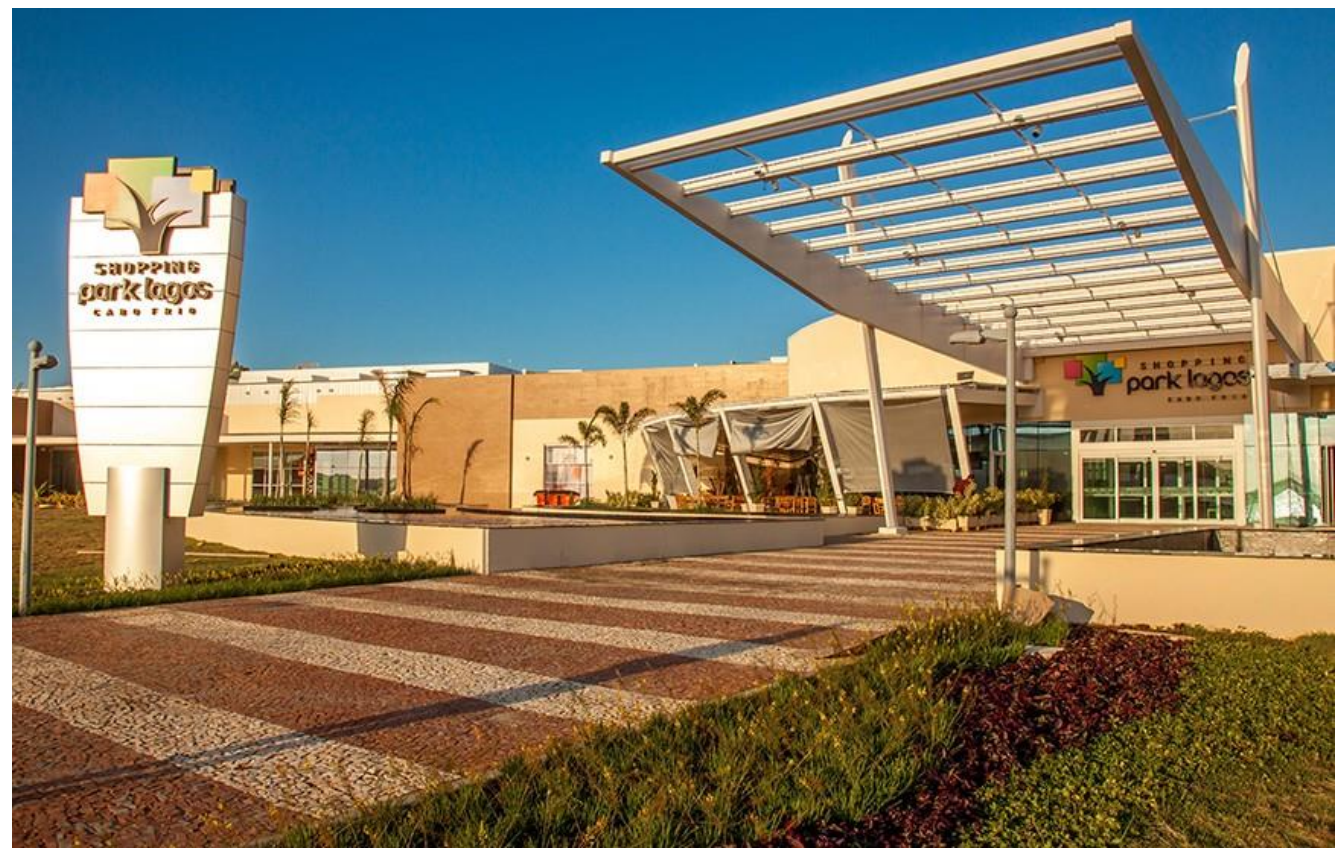

Imagem 2: Shopping Park Lagos: símbolo da urbanização recente. Fonte: http://www.argopar.com.br/os-shoppings/shopping-park-lagos, em 23 de outubro de 2017.

Cabo Frio prosperou com a imagem de alegria, de calor, de lindas praias, de lazer, onde as mazelas e injustiças sociais desaparecem em uma verdadeira cidadesimulacro. Assim, os empreendimentos de lazer situados nas áreas gastronômicas da cidade apresentam cardápios com valores incompatíveis com a condição financeira da maioria da população. Da mesma maneira, os acessos rodoviários se afastam da periferia e levam o turista para o centro e para a orla, como a linha de ônibus para o shopping Park Lagos, que atravessa alguns bairros nas proximidades do shopping e o centro da cidade, fazendo com que a população residente em vários bairros periféricos da cidade necessite de duas conduções - e, portanto, do pagamento de duas passagens para chegar até o shopping.

Por sua vez, os mapas turísticos excluem as áreas mais pobres, que desaparecem das multicoloridas cartas setorizadas; a nova ponte construída sobre o Canal do Itajuru é um acesso que inibe a chegada aos bairros pobres ao direcionar o motorista, em mão única, à emergente região do Peró. Há um notório ocultamento da periferia, especificamente de bairros como Jardim Esperança, Tangará, Guriri e Jacaré, entre outros, que permanecem convivendo com graves problemas sociais, como o desemprego, subemprego e a violência urbana, bem como de ordem habitacional, de fornecimento de água e de saneamento básico. A combinação da crise dos royalties com o próprio momento econômico brasileiro, em profunda crise desde o golpe jurídicoparlamentar de 2016, ampliaram o fosso que separa as áreas centrais e turistificadas da cidade, mesmo com o impacto dos desinvestimentos, e a periferia, que conhece as dores 
da explosão da violência urbana combinadas com os anátemas da crise econômica multiescalar.

É fatídico que encontremos nos interstícios da riqueza aparente a dura realidade dos excluídos. Conforme nos ensina Francisco de Oliveira (2003), não há atraso, mas sim as evidências concretas das dores do modelo de desenvolvimento. E por mais que se busque eclipsar as contradições, o caráter ubíquo da paisagem faz com que revelem em toda sua plenitude e intensidade. Nesta sociedade planejadamente segregada, o que os governantes e empresários nomeiam como se consolida, em Cabo Frio, como um privilégio de poucos, cuidadosamente selecionados.

\section{Considerações Finais}

Nas últimas décadas, um conjunto de transformações gerais do capitalismo afetou profundamente a forma de conceber e realizar o planejamento urbano: as cidades reconquistaram autonomia e importância, adquirindo crescente protagonismo (MARICATO, 2000). Na disputa pela captação de recursos, são produzidas imagens sedutoras por meio de um agressivo city marketing gerando uma verdadeira guerra dos lugares no âmbito regional (SANTOS, 1996). Ao seu modo, Cabo Frio vem participando deste processo.

O processo de reestruturação em Cabo Frio baseado na urbanização turística mostrou-se socialmente, economicamente e ambientalmente insustentável. Diante desse processo aparentemente avassalador de urbanização turística, capaz de superar antigas atividades econômicas da cidade, o meio ambiente passou a ser ponto nevrálgico, pois é um fator que impulsiona atividade turística da cidade, transformado o sol, na praia, o calor, as dunas, a lagoa e os espaços verdes em mercadorias. Ao mesmo tempo, os impactos ambientais são frutos desse processo de urbanização que amplia a precificação a natureza, algo facilmente constatável nas últimas décadas na cidade pelo surgimento de aterros, pela poluição da lagoa e pela diminuição da extensão das dunas, além de impactos em áreas de manguezal e restinga. A edificação do Shopping Park Lagos, construído em uma área de proteção ambiental e local de sambaquis, revela a supremacia dos interesses políticos e econômicos sobre necessidade de preteção das riquezas naturais. As consequências da degradação ambiental em larga escala são justificadas pelo inevitável processo de urbanização turística da cidade, que carregaria consigo, evidentemente, crescimento econômico.

Por outro lado, os investimentos realizados nas últimas décadas em Cabo Frio durante as administrações de Alair Correa e Marcos da Rocha Mendes enquadraram a cidade naquilo que Sérgio Molina determinou como ludópolis (MOLINA, 2003), ou seja, como um centro lúdico de diversão, lazer e entretenimento. As intervenções na cidade constituíram um território adequado para oferecimento de um produto pasteurizado para grandes grupos de turistas, em um mundo de ilusões e lugares imaginários que não são natos, mas, que por persistência, acabaram por se fundir a cultura local (CAVALCANTI, 2004). Conforme ensinado por Fernanda Sánchez (2003), as estratégias de marketing urbano utilizadas pelas lideranças locais se tornaram de fundamental importância para a divulgação dos atributos dos diferentes lugares e das imagens construídas; são criados verdadeiros cenários, que na maioria das vezes, omitem a realidade, aumentando a capacidade de atratividade do produto cidade, transformando os cidadãos em meros figurantes, algo como atores secundários de seu roteiro.

Não é por outro motivo que o acesso aos pressupostos deste lazer é progressivamente discriminatório e excludente, sendo voltado para públicos específicos 
capazes de consumir o que lhes é oferecido. Mas, evidentemente, isto não impede a constituição de um sentimento universalizante de uma cidade alegre e festiva, que fez a população local acreditar que as ações e objetos criados nesta perspectiva tenham reverberado na melhoria de vida de todos.

A cidade de Cabo Frio se consolidou como cidade média e centro de serviços regional, bem como implementou inúmeras melhorias infraestruturais em seu tecido urbano. Todavia, mesmo com as caudalosas rendas do petróleo e com a visita de milhões de turistas anuais, a cidade permanece com graves problemas sociais e dificuldades urbanas que poderiam ter recebido, em algum momento, maior atenção dos governos municipais. Colocada em julgamento neste breve balanço, a urbanização turística não permitiu transformar Cabo Frio numa cidade mais democrática no campo da política, sustentável ambientalmente e socialmente mais justa.

\section{Notas:}

1 - Para maiores informações, consultar: NUNES, Nathan da Silva; RIBEIRO, Miguel Ângelo. A geografia da atividade turística no território fluminense: uma releitura. Geo UERJ, [S.1.], n. 36, p. e48407, fev. 2020. ISSN 1981-9021. Disponível em: https://www.epublicacoes.uerj.br/index.php/geouerj/article/view/48407/32333. Acesso em: 14 de maio de 2020.

2 - Para maiores informações, consultar: LOUZADA, Victor Miranda Louzada. Quando o sambaqui vira shopping center: a produção social do espaço a partir da urbanização turística em Cabo Frio. 2018. Dissertação (Mestrado em Geografia) - programa de Pós-Graduação em Geografia, Universidade do Estado do Rio de Janeiro.

\section{Referências Bibliográficas}

ALVES, M. R. da Silva. Conjunto Paisagístico de Cabo Frio. In: XII Simpurb, Belo Horizonte, MG, 2011.

ANDRADE, Thompson Almeida; SERRA, Rodrigo Valente (orgs.). Cidades Médias Brasileiras. Rio de Janeiro, Instituto de Pesquisa Econômica Aplicada (Ipea), 2001.

BAPTISTA, José Correia. A longa marcha - A dominação política da oposição em Cabo Frio após o Golpe de 1964. Cabo Frio: Ed. Jornal de Sábado, 2007.

CAVALCANTI, Márcia Maria. O fetiche do consumo como agente de reprodução do não-lugar. In: Revista Turismo. [Revista On-Line] Dezembro - 2004. Disponível em: http://revistaturismo.cidadeinternet.com.br/artigos/nao-lugar.html. Acesso em 30 de janeiro de 2007.

CHAUÍ, Marilena. O que é Ideologia. 9. Ed. São Paulo, Editora Brasiliense, 1982.

CHOAY, Françoise. O Urbanismo em Questão. São Paulo: Ed. Perspectiva, 1979.

CHRISTÓVÃ̃, J. H. de O. Do sal ao sol: a construção social da imagem do turismo em Cabo Frio. 2011. Dissertação (Mestrado) - Faculdade de Formação de Professores, Universidade do Estado do Rio de Janeiro, São Gonçalo, 2011.

COMPANS, Rose. Empreendedorismo urbano: entre o discurso e a prática. São Paulo: Editora UNESP, 2004.

CONCEIÇÃO, Carolina dos Santos. Os Impactos do Ginásio Poliesportivo Aracy Machado no Processo de Urbanização Turística de Cabo Frio. 2008. Trabalho de Conclusão de Curso. (Graduação em Licenciatura Plena em Geografia) - Fundação Educacional da Região dos Lagos.

DANTAS, E.; FERREIRA, A. CLEMENTINO, M. (orgs.) Turismo e imobiliário nas metrópoles. Rio de Janeiro: Letra Capital, 2010.

FENNELL, David. A Natureza do Turismo. In: Ecoturismo: Uma Introdução. São Paulo, Contexto, 2002. 
FRATUCCI, Aguinaldo César. Os Lugares Turísticos: Territórios do Fenômeno Turístico. In: Geographia, Revista do Programa de Pós-Graduação em Geografia da UFF. (Ano II, n. ${ }^{\circ}$ ) Niterói/RJ: UFF/EGG, 2001.

GEORGE, Pierre. O Meio Ambiente. São Paulo: Difusão Europeia do livro, Saber Atual, 1973.

GONÇALVES, Leonardo de Freitas. Pesca: o mar como fonte de recursos em Cabo Frio - RJ. In: MARAFON, Glaúcio José; RIBEIRO, Miguel Ângelo. (orgs.). Revisitando o Território Fluminense. Rio de Janeiro: NEGEF, 2003.

HARVEY, David. A Produção Capitalista do Espaço. São Paulo: Editora Annablume, 2005.

HARVEY, David. Do gerenciamento ao "empresariamento": a transformação da administração urbana no capitalismo tardio. In: Espaço \& Debate. São Paulo: Núcleo de Estudos Regionais e Urbanos, $\mathrm{n}^{\circ} 36,1996, \mathrm{pp}$. 48-64.

JAMESON, F. Pós-modernismo: a lógica cultural do capitalismo tardio. São Paulo: Ática, 2000.

KNAFOU, Remy. Le urbain et le tourisme: une construction laborieuse. In: KNAFOU, Rémy e DUHAMEL, Philipe (orgs.) Mondes urbaines du tourisme. Paris: Belin, 2008, pp.9-21.

LEFEBVRE, Henri. O direito à cidade. 4. ed. São Paulo: Centauro, 2006 [1968].

LENCIONI, Sandra. Urbanização difusa e a constituição de megarregiões: O caso de São Paulo-Rio de Janeiro. E-metropolis: Revista Eletrônica de Estudos Urbanos e Regionais, ano 6, n. ${ }^{\circ}$ 22, setembro de 2015. Disponível em: http://www.emetropolis.net/index.php?option=com_edicoes\&task=artigos\&id=132\&lan $\mathrm{g}=\mathrm{pt}$. Acesso em: 05 de dezembro de 2015.

LOPES Jr., Edmilson. "Urbanização turística, cultura e meio ambiente no nordeste brasileiro". In: BRUHNS, Heloísa e SERRANO, Célia (org.) Viagens à natureza: turismo, cultura e ambiente. 3. Ed. São Paulo: Papirus, 2000, p.43-58.

LOUZADA, Victor Miranda Louzada. Quando o sambaqui vira shopping center: a produção social do espaço a partir da urbanização turística em Cabo Frio. 2018. Dissertação (Mestrado em Geografia) - programa de Pós-Graduação em Geografia, Universidade do Estado do Rio de Janeiro.

LUCHIARI, Maria Tereza D. P. Urbanização turística: um novo nexo entre o lugar e o mundo. In: LIMA, Luiz C. (org.). Da Cidade ao Campo: a diversidade do saber-fazer turístico. Fortaleza: UECE, 1998, p.15-29.

MARAFON, Glaucio. [et al.]. Regiões de Governo do Estado do Rio de Janeiro: Uma Contribuição Geográfica. Rio de Janeiro, Gramma, 2005, p. 56.

MARICATO, Ermínia. As ideias fora do lugar e o lugar fora das ideias: planejamento urbano no Brasil. In: MARICATO, Ermínia; ARANTES, O.; e VAINER, C. A Cidade do Pensamento Único - Desmanchando Consensos. 3. Ed. Petrópolis, Editora Vozes, 2000.

MASCARENHAS, Gilmar. Cenários contemporâneos da urbanização turística. In: Caderno Virtual de Turismo. COPPE/UFRJ, Rio de Janeiro, dezembro / 2004.

MASCARENHAS, Gilmar; OLIVEIRA, Leandro Dias de. Cidades Saudáveis e Competitivas: Políticas Públicas, Esporte e City Marketing. In: II Simpósio Internacional Cidades Médias, 2006, Uberlândia. Anais [do] II Simpósio Internacional sobre Cidades Médias: Dinâmica Econômica e Produção do Espaço Urbano. Uberlândia - MG: Universidade Federal de Uberlândia, UFU, Instituto de Geografia, 2006.

MASSEY, D. World City. London: Potety Press, 2007.

MENEZES, Thaiana Silva Lima de. A Economia dos Royalties em Cabo Frio: Planejamento Urbano-Turístico e Mudanças Socioespaciais. 2008. Trabalho de 
Conclusão de Curso. (Graduação em Licenciatura Plena em Geografia) - Fundação Educacional da Região dos Lagos.

MOLINA, Sergio. O Pós-Turismo. São Paulo: Aleph, 2003.

MULLINS, Patrick. Tourism urbanization. International Journal of Urban Regional Research, 15 (3): 326-342, 1991.

NUNES, Nathan da Silva; RIBEIRO, Miguel Ângelo. A geografia da atividade turística no território fluminense: uma releitura. Geo UERJ, [S.1.], n. 36, p. e48407, fev. 2020. ISSN 1981-9021. Disponível em: https://www.epublicacoes.uerj.br/index.php/geouerj/article/view/48407/32333. Acesso em: 14 de maio de 2020.

OLIVEIRA, Elizângela. Turismo, produção do espaço e planejamento urbano nas cidades contemporâneas. Turismo: Estudos \& Práticas (RTEP/UERN), Mossoró/RN, vol. 3, n. 2, jul./dez. 2014. Disponível em: http://periodicos.uern.br/index.php/turismo. Acesso em: 26 de fevereiro de 2018.

OLIVEIRA, Floriano José Godinho de. Reestruturação Produtiva e Regionalização da Economia no Território Fluminense, 2003. Tese (Doutorado em Geografia Humana). Departamento de Geografia da Faculdade de Filosofia, Letras e Ciências Humanas, Universidade de São Paulo, São Paulo.

OLIVEIRA, Francisco de. Crítica à razão dualista - o ornitorrinco. São Paulo: Boitempo Editorial, 2003.

OLIVEIRA, Leandro Dias de; RIBEIRO, Guilherme. As Territorialidades da Metrópole no Século XXI: Tensões entre o Tradicional e o Moderno na Cidade de Cabo Frio-RJ.

Geo UERJ, v. 3, p. 108-127, 2009. Disponível em: http://www.epublicacoes.uerj.br/index.php/geouerj/article/viewFile/1431/1209. Acesso em: 12 de dezembro de 2017.

PESSANHA, Roberto Moraes. A ampliação da fronteira de exploração petrolífera no Brasil é parte da geopolítica da energia: oportunidades e riscos de inserção global em meio às novas territorialidades regionais e ao desafio da abundância na economia dos royalties no Estado do Rio de Janeiro. Espaço e Economia: Revista Brasileira de Geografia Econômica, Ano III, N. 6, 2015. Disponível em: https://journals.openedition.org/espacoeconomia/1511. Acesso em: 12 de dezembro de 2017.

PORTO-GONÇALVES, Carlos Walter. A Invenção de Novas Geografias. In: Programa de Pós-Graduação em Geografia - PPGEO. Território Territórios. Niterói / RJ, UFF/AGB, 2002.

RAMÃO, Felipe de Souza. A mercantilização do meio ambiente na cidade de Cabo Frio a partir dos fundamentos de Pierre George. 2015. (dissertação de mestrado) Universidade do Estado do Rio de Janeiro, Faculdade de Formação de Professores.

SÁNCHEZ, Fernanda. A Reinvenção das Cidades para um Mercado Mundial. Chapecó: Editora Argos, 2003.

SANTOS, Milton. A Urbanização Brasileira. São Paulo, HUCITEC, 1993.

SOUZA, Marcelo. Cidades, globalização e determinismo econômico. In: Cidades, v. 3, n. 5, 2006, p. 123-142.

SPOSITO, Maria Encarnação Beltrão. Espaços urbanos: territorialidades e representações. In: SPOSITO, Eliseu (org.). Dinâmica econômica, poder e novas territorialidades. Presidente Prudente, UNESP: GASPERR, 1999.

SPOSITO, Eliseu Savério; SPOSITO, Maria Encarnação Beltrão; SOBARZO, Oscar. Cidades Médias: produção do espaço urbano e regional. São Paulo: Expressão Popular, 2006.

WEED, M. Olympic Tourism. Oxford: Elsevier, 2008. 